\title{
Andrographolide, a Novel NF- $\kappa$ B Inhibitor, Induces Vascular Smooth Muscle Cell Apoptosis via a Ceramide-p47phox-ROS Signaling Cascade
}

\author{
Yu-Ying Chen, ${ }^{1}$ Ming-Jen Hsu, ${ }^{2}$ Joen-Rong Sheu, ${ }^{1,2}$ Lin-Wen Lee, ${ }^{3}$ and Cheng-Ying Hsieh ${ }^{1,2}$ \\ ${ }^{1}$ Graduate Institute of Medical Sciences, School of Medicine, Taipei Medical University, 250 Wu-Hsing Street, Taipei 11031, Taiwan \\ ${ }^{2}$ Department of Pharmacology, School of Medicine, Taipei Medical University, 250 Wu-Hsing Street, Taipei 11031, Taiwan \\ ${ }^{3}$ Department of Microbiology and Immunology, Taipei Medical University, 250 Wu-Hsing Street, Taipei 11031, Taiwan
}

Correspondence should be addressed to Lin-Wen Lee; lucie@tmu.edu.tw and Cheng-Ying Hsieh; hsiehcy@tmu.edu.tw

Received 30 October 2013; Accepted 4 December 2013

Academic Editor: Mao-Hsiung Yen

Copyright ( 2013 Yu-Ying Chen et al. This is an open access article distributed under the Creative Commons Attribution License, which permits unrestricted use, distribution, and reproduction in any medium, provided the original work is properly cited.

\begin{abstract}
Atherosclerosis is linked with the development of many cardiovascular complications. Abnormal proliferation of vascular smooth muscle cells (VSMCs) plays a crucial role in the development of atherosclerosis. Accordingly, the apoptosis of VSMCs, which occurs in the progression of vascular proliferation, may provide a beneficial strategy for managing cardiovascular diseases. Andrographolide, a novel nuclear factor- $\kappa \mathrm{B}$ inhibitor, is the most active and critical constituent isolated from the leaves of Andrographis paniculata. Recent studies have indicated that andrographolide is a potential therapeutic agent for treating cancer through the induction of apoptosis. In this study, the apoptosis-inducing activity and mechanisms in andrographolide-treated rat VSMCs were characterized. Andrographolide significantly induced reactive oxygen species (ROS) formation, p53 activation, Bax, and active caspase- 3 expression, and these phenomena were suppressed by pretreating the cells with $\mathrm{N}$-acetyl-L-cysteine, a ROS scavenger, or diphenylene iodonium, a nicotinamide adenine dinucleotide phosphate (NADPH) oxidase (Nox) inhibitor. Furthermore, p47phox, a Nox subunit protein, was phosphorylated in andrographolide-treated rat VSMCs. However, pretreatment with 3-O-methyl-sphingomyelin, a neutral sphingomyelinase inhibitor, significantly inhibited andrographolide-induced $\mathrm{p} 47 \mathrm{phox}$ phosphorylation as well as Bax and active caspase-3 expression. Our results collectively demonstrate that andrographolide-reduced cell viability can be attributed to apoptosis in VSMCs, and this apoptosis-inducing activity was associated with the ceramidep47phox-ROS signaling cascade.
\end{abstract}

\section{Introduction}

Atherosclerosis remains a major and increasing health concern in developed countries, although prevention strategies have substantially increased. Consequently, developing novel therapeutic agents for atherosclerosis patients remains a major research priority [1]. Aberrant vascular smooth muscle cells (VSMCs) proliferation has been shown to play a critical role in the pathogenesis of atherosclerosis-related events including in-stent restenosis, restenosis after percutaneous transluminal angioplasty, transplant vasculopathy, and vein bypass graft failure $[2,3]$. Therefore, inhibition of VSMC proliferation might be a major target for the treatment of cardiovascular diseases. Apoptosis, or the programmed cell death of VSMCs, which occurs in the pathogenesis and progression of vascular proliferative disorders, such as atherosclerosis and restenosis, often represents a critical feature of blood vessel remodeling [4]. In addition, neointima development and lesion growth in VSMCs seem to be restrained by late apoptosis [5]. The regulated balance between the death and survival signals perceived by a cell is used to control the initiation of apoptosis [6]. Because cell apoptosis can inhibit the proliferation of VSMCs, inducing apoptosis may provide a pharmacological basis for treating proliferative cardiovascular disorders.

Increased reactive oxygen species (ROS) production is known to play a vital role in VSMC proliferation and apoptosis and leads to the development of atherosclerosis. The 
apoptosis of VSMCs caused by enhanced ROS production affects the progression of atherosclerotic lesions and may induce plaque rupture [7]. ROS are small, extremely reactive molecules because of their unpaired valence electrons. There are several intracellular ROS producers, including 2 main manufacturers, the mitochondria and nicotinamide adenine dinucleotide phosphate (NADPH) oxidase. A rapidly expanding body of experimental evidence gathered since the first identification of VSMCs implicates that NADPH oxidase (Nox) in vascular cells is the underlying cause of oxidative stress in various cardiovascular diseases [8]. Nox is a complex composed of membrane-bound (p22phox and Noxl-4) and cytoplasmic (Rac, p47phox, and p67phox) subunits. When it is activated, cytoplasmic subunits connect with their membrane-bound counterparts and generate an active complex that oxidizes NADPH, leading to the production of ROS [9]. The Nox-dependent production of ROS is thought to be a crucial regulator of smooth muscle cell viability and is believed to be linked to the development and severity of human atherosclerotic lesions [10].

Andrographolide (Figure 1), a novel nuclear factor $-\kappa \mathrm{B}$ (NF- $\kappa \mathrm{B})$ inhibitor, is the most active and critical constituent isolated from the leaves of Andrographis paniculata [11]. A. paniculata has long been used as a herbal medicine to prevent and treat upper respiratory tract infections, diarrhea, rheumatoid arthritis, and laryngitis in Asia and Scandinavia [11, 12]. Recent studies have indicated that andrographolide inhibits tumor growth by inducing cell cycle arrest $[13,14]$ or apoptosis $[15,16]$ in various types of cancer cells. Recently, our previous study confirmed that andrographolide enhances NF- $\kappa$ B subunit p65 Ser536 dephosphorylation through neutral sphingomyelinase (nSMase)-mediated ceramide formation in VSMCs [17], involving an increase in cyclic GMP/PKG, followed by the inhibition of the p38MAPK/HO${ }^{-}-\mathrm{NF}-\kappa \mathrm{B}-$ ERK2 cascade in activated platelets $[18,19]$. However, andrographolide has demonstrated antiproliferative and apoptotic effects on various types of cancer cells, whether it induces apoptosis in VSMCs is not known. Furthermore, ROS appear to mediate the apoptosis-inducing activity of andrographolide, but the source of ROS formation in andrographolide-induced apoptosis remains unclear. In the present study, by considering the pivotal role of abnormal VSMC proliferation in the development of atherosclerosis and restenosis, we examined the detailed cellular signaling events associated with andrographolide-induced VSMC apoptosis.

\section{Materials and Methods}

2.1. Materials. Dulbecco's modified Eagle's medium (DMEM), trypsin (0.25\%), L-glutamine, penicillin/streptomycin, and fetal bovine serum (FBS) were purchased from Gibco (Gaithersburg, MD, USA). Andrographolide ( $\geq 98 \%$ ), 3-(4,5-dimethylthiazol-2-yl)-2,5-diphenyltetrazolium bromide (MTT), N-acetyl-L-cysteine (NAC), diphenyleneiodonium chloride (DPI), 2,7-dichlorofluorescein diacetate (DCF-DA), and dimethyl sulfoxide (DMSO) were obtained

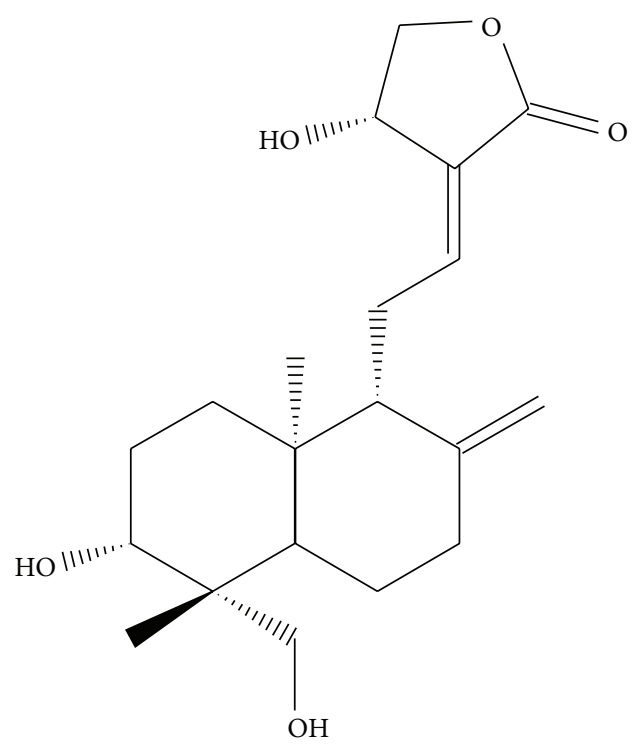

Figure 1: Chemical structure of andrographolide (Andro).

from Sigma-Aldrich (St. Louis, MO, USA). The 3-O-methylsphingomyelin (3-OMS) was purchased from Biomol (Plymouth Meeting, PA, USA). Anti-caspase-3 monoclonal antibodies (mAbs) and anti-Bax polyclonal antibody (pAb) were obtained from cell signaling (Beverly, MA, USA); the anti-phospho-p47phox serine359 pAb was acquired from Abcam (Cambridge, MA, USA); the anti- $\alpha$-tubulin $\mathrm{mAb}$ was obtained from NeoMarkers (Fremont, CA, USA). The hybond-P polyvinylidene difluoride (PVDF) membrane, enhanced chemiluminescence (ECL) Western blotting detection reagent and analysis system, horseradish peroxidase (HRP)-conjugated donkey anti-rabbit immunoglobulin $\mathrm{G}$ (IgG), and sheep anti-mouse IgG were acquired from Amersham (Buckinghamshire, UK). Andrographolide was dissolved in $0.1 \%$ dimethyl sulfoxide (DMSO) and stored at $4^{\circ} \mathrm{C}$ until used.

2.2. Rat Aortic Smooth Muscle Cell Primary Culture. The male Wistar rats used in this study were purchased from BioLASCO (Taipei, Taiwan). The VSMCs were enzymatically dispersed from the male Wistar rats (250-300 g). Thoracic aortas from the Wistar rats were removed and stripped of endothelium and adventitia. The VSMCs were obtained using a modification of the combined collagenase and elastase digestion method [20]. These cells were grown in DMEM supplemented with $20 \mathrm{mM}$ HEPES, 10\% FBS, 1\% penicillin/streptomycin, and $2 \mathrm{mM}$ glutamine at $37^{\circ} \mathrm{C}$ in a humidified atmosphere of $5 \% \mathrm{CO}_{2}$. The growth medium was changed every 2-3 days until the cells reached confluence. The growth medium was removed, and the monolayer was rinsed with phosphate-buffered saline (PBS). A trypsinEDTA solution was added, and the monolayer was incubated at $37^{\circ} \mathrm{C}$ for $2 \mathrm{~min}$. The culture dishes were observed under a phase-contrast microscope until the cells detached. The cells were removed using $10 \mathrm{~mL}$ of DMEM and centrifuged at $900 \mathrm{rpm}$ for $7 \mathrm{~min}$. The pellet was resuspended in DMEM 
in a culture dish, and cells from Passages 4-8 were used in all experiments. The primary cultured rat aortic VSMCs showed the "hills and valleys" pattern, and the expression of $\alpha$-smooth muscle actin was confirmed (data not shown). All protocols were approved by the Taipei Medical University Animal Care and Use Committee.

2.3. Cell Viability Assay. The VSMCs $\left(2 \times 10^{4}\right.$ cells/well $)$ were seeded on 24-well plates and cultured in DMEM containing $10 \%$ FBS for $24 \mathrm{~h}$. The VSMCs were pretreated with NAC $(1 \mathrm{mM})$ before being treated with andrographolide $(50 \mu \mathrm{M})$ for $48 \mathrm{~h}$. The cell number was measured using a colorimetric assay based on the ability of mitochondria in viable cells to reduce MTT as previously described [21]. The cell number index was calculated as the absorbance of treated cells/control cells $\times 100 \%$.

2.4. Measurement of Intracellular ROS. The VSMCs $\left(5 \times 10^{5}\right.$ cells/dish) were loaded with DCF-DA $(20 \mu \mathrm{M})$ for $20 \mathrm{~min}$ and then treated following the experimental design. These cells were washed with PBS before trypsinization. The levels of intracellular ROS were detected using Coulter Epics XL flow cytometry (Beckman Coulter, Miami, FL, USA). Data were collected from 10,000 cells per experimental group. All experiments were repeated at least 4 times to ensure reproducibility.

2.5. Immunoblot Analysis. Immunoblot analyses were performed as described previously [20]. Briefly, the VSMCs $(5 \times$ $10^{5}$ cells/dish) were treated as the experimental design. After the experimental period, the proteins were extracted using a lysis buffer. Lysates were centrifuged, the supernatant protein $(50 \mu \mathrm{g})$ was collected and subjected to sodium dodecyl sulfate-polyacrylamide gel electrophoresis (SDS-PAGE), and the separated proteins were electrophoretically transferred onto $0.45 \mu \mathrm{m}$ PVDF membranes by using semidry transfer (Bio-Rad, Hercules, CA, USA). The blots were blocked with TBST (10 mM Tris-base, $100 \mathrm{mM} \mathrm{NaCl}$, and 0.01\% Tween 20) containing $5 \%$ bovine serum albumin for $1 \mathrm{~h}$ and then probed with various primary antibodies. The membranes were incubated with HRP-linked anti-mouse IgG or anti-rabbit IgG (diluted 1:3000 in TBST) for $1 \mathrm{~h}$. The immunoreactive bands were detected using an ECL system. Bar graphs depict the ratios of quantitative results obtained by scanning the reactive bands and quantifying the optical density by using video densitometry (Bio-Profil; Biolight Windows application version 2000.01; Vilber Lourmat, France).

2.6. Transfection and Luciferase Reporter Assays. The cells were transfected with PG13-luc and Renilla-luc plasmids using the Turbofect reagent. The treated and untreated cells were harvested, and the luciferase activity level was determined using the Dual-Glo luciferase assay system kit. The luciferase activity level was normalized based on the Renilla luciferase activity level. The level of luciferase activity was quantified as the ratio of the activity of cells treated with andrographolide to that of the untreated control cells.
2.7. Statistical Analysis. The experimental results are expressed as the means \pm standard error and are accompanied by the number of observations. Data were assessed using an analysis of variance. If an analysis indicated significant differences among the group means, then each group was compared with the others using the Newman-Keuls method. Values of $P<0.05$ were considered statistically significant.

\section{Results}

3.1. The Role of ROS in Andrographolide-Reduced Cell Viability in Rat VSMCs. We previously determined that andrographolide resulted in loss of cell viability in a concentrationdependent manner by using an MTT assay (unpublished data). However, the detailed mechanism involved in this phenomenon remains unclear. ROS formation is known to play a crucial role in cell apoptosis [7]. Therefore, we investigated the role of ROS in andrographolide-induced VSMC death. Figure 2(a) shows that treatment with $50 \mu \mathrm{M}$ andrographolide significantly induced ROS formation $1.5 \pm 0.0$ fold at 10 min compared with the control group $(P<0.001$, $n=4)$. We subsequently preincubated with NAC $(1 \mathrm{mM})$ an ROS scavenger, in andrographolide-treated VSMCs. Figure 2(b) shows that treatment with andrographolide reduced the cell viability of rat VSMCs to $46.9 \pm 6.6 \%$ compared with the control group $(P<0.001, n=4)$, whereas pretreatment with $1 \mathrm{mM}$ NAC significantly reversed the andrographolideinduced reduction in VSMC viability $(P<0.001, n=4)$. Taken together, these data suggest that the reduction of cell viability in andrographolide-treated rat VSMCs was related to the cellular redox state, possibly as a consequence of ROS formation.

\subsection{Nox-Mediated Redox Signaling in Andrographolide-} Induced ROS Formation. Coronary artery restenosis, a frequent complication of angioplasty, is accompanied by an increase in Nox-generated ROS production [22]. Therefore, we investigated the involvement of Nox-mediated signaling in andrographolide-induced ROS formation. In Figure 3(a), pretreatment with NAC $(1 \mathrm{mM})$ or DPI $(10 \mu \mathrm{M})$, a Nox inhibitor, significantly suppressed andrographolide-induced ROS formation. Furthermore, growing evidence has suggested that the activation of the Nox subunit p47phox is required for ROS production in vascular cells [23]. We subsequently determined whether Nox subunit activation is required for andrographolide-induced ROS production in rat VSMCs. As shown in Figure 3(b), serine359 phosphorylation of the p47phox subunits was significantly increased $1.6 \pm 0.1$-fold after andrographolide stimulation for $10 \mathrm{~min}$ compared with the control group $(P<0.01, n=3)$. These results suggest that phosphorylation of the Nox subunit $\mathrm{p} 47$ phox mediates ROS formation in rat VSMCs treated with andrographolide.

\subsection{Effects of ROS Scavengers on Andrographolide-Stimulated} p53 Activation, Bax, and Active Caspase-3 Expression in Rat VSMCs. It is known that oxidative stress triggers the activation and nuclear translocation of p53 [24], and p53-induced 


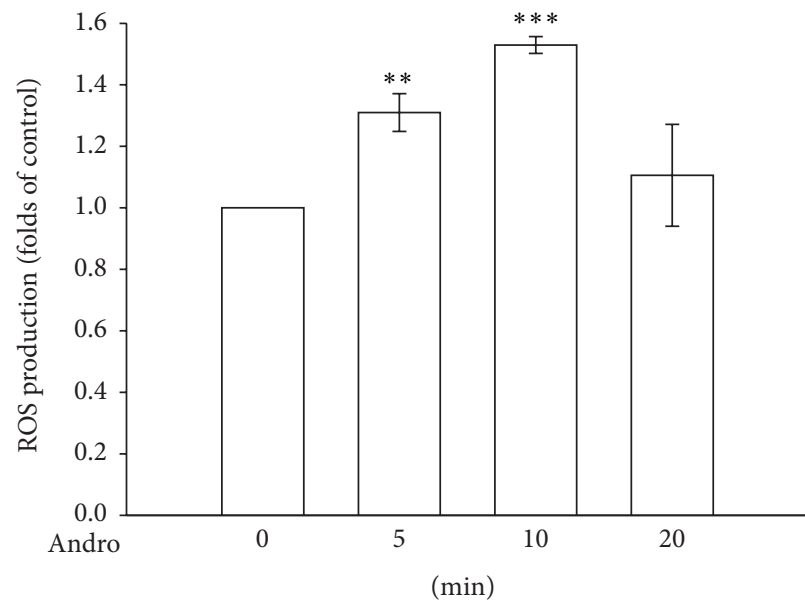

(a)

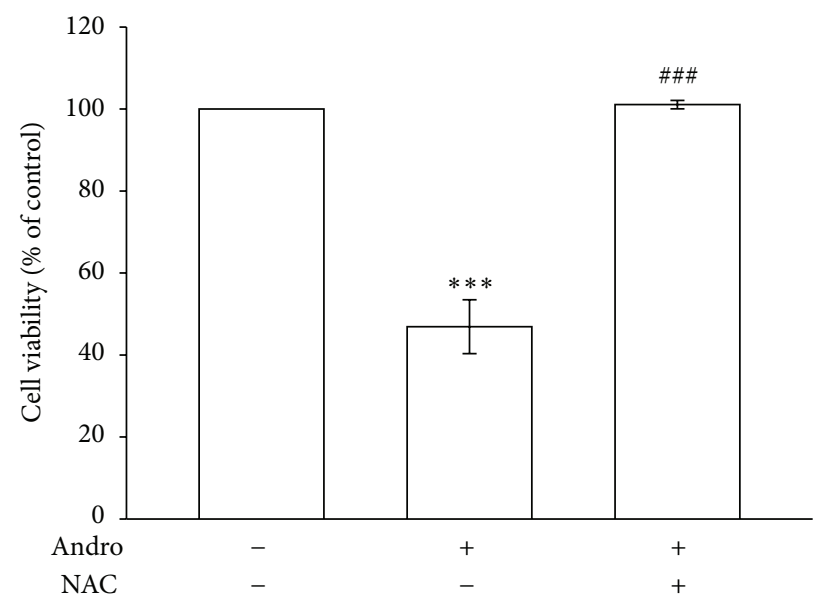

(b)

FIGURE 2: The role of ROS in andrographolide-reduced cell viability in rat VSMCs. (a) Rat VSMCs were treated with $50 \mu \mathrm{M}$ andrographolide for the indicated periods. Cells were harvested, and the formation of ROS was examined using flow cytometric analysis of DCF-DAstained cells, as described in Section 2. (b) Cells were pretreated with a vehicle or $1 \mathrm{mM}$ NAC for 30 min before being treated with $50 \mu \mathrm{M}$ andrographolide for $48 \mathrm{~h}$; cell viability was subsequently determined using an MTT assay. The results shown are representative of 4 independent experiments. The data are presented as the mean \pm SEM (error bars: ${ }^{* *} P<0.01$ and ${ }^{* * *} P<0.001$, compared with the control group, and ${ }^{\# \# \#} P<0.001$, compared with the group treated only with andrographolide).

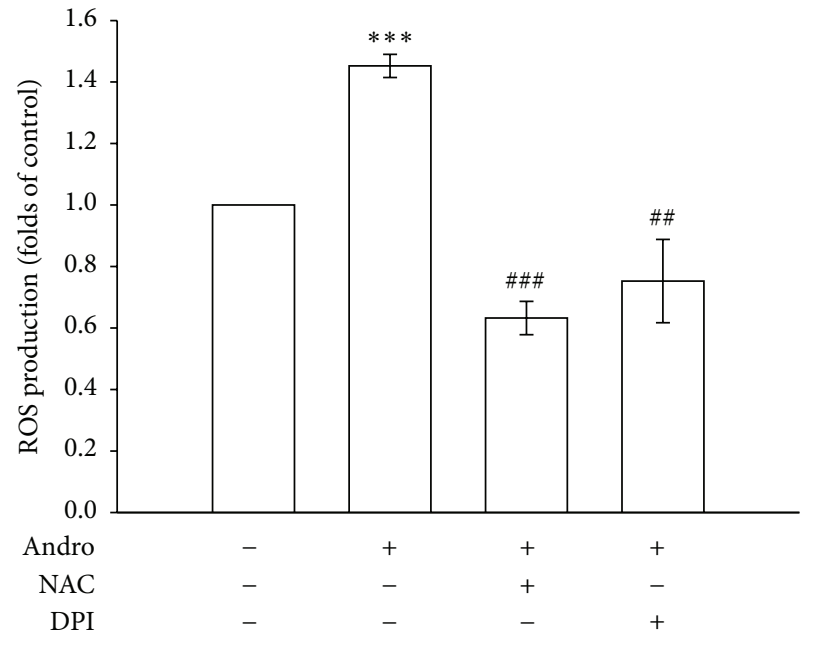

(a)
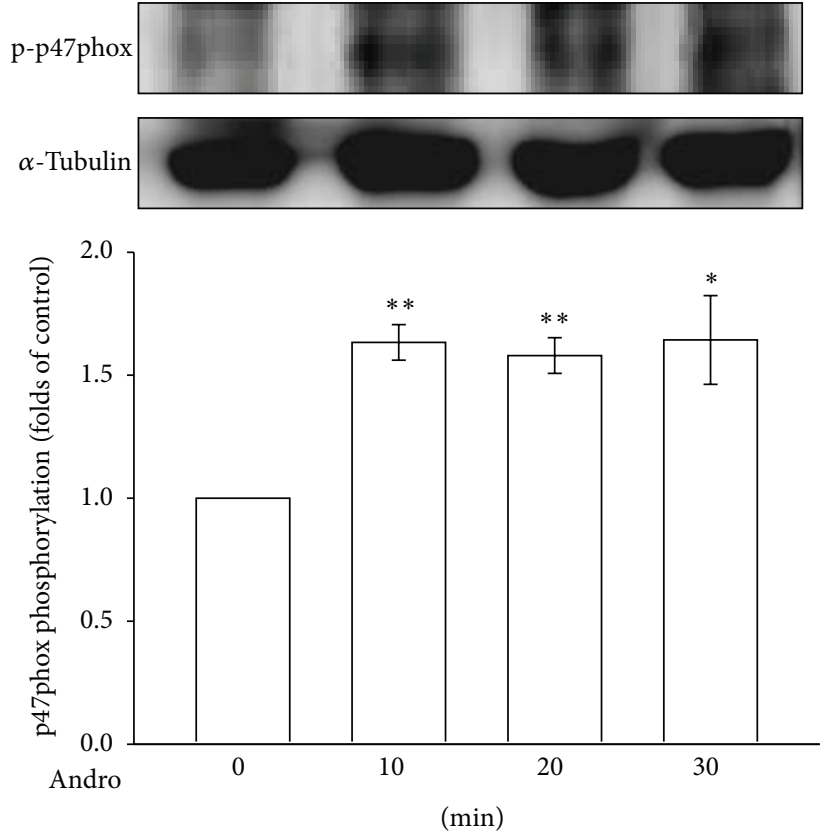

(b)

FIGURE 3: Nox-mediated redox signaling in andrographolide-induced ROS formation. (a) Cells were pretreated with a vehicle, $1 \mathrm{mM}$ NAC, or $10 \mu \mathrm{M}$ DPI for $30 \mathrm{~min}$ before being treated with $50 \mu \mathrm{M}$ andrographolide for $10 \mathrm{~min}$, and the production of ROS was examined using flow cytometric analysis of DCF-DA-stained cells, as described in Section 2. (b) Cells were treated with $50 \mu \mathrm{M}$ andrographolide for the indicated periods. Cells were harvested, and the phosphorylation of $\mathrm{p} 47$ phox was examined using immunoblotting. The data are presented as the mean \pm SEM (error bars: ${ }^{*} P<0.05,{ }^{* *} P<0.01$, and ${ }^{* * *} P<0.001$, compared with the control group, and ${ }^{\# \#} P<0.01$ and ${ }^{\# \# \#} P<0.001$, compared with the group treated only with andrographolide). 


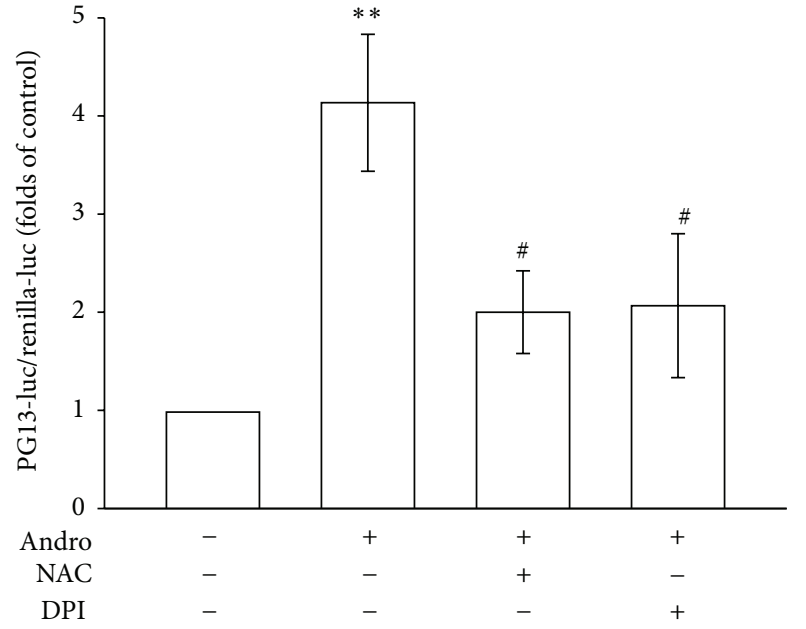

(a)

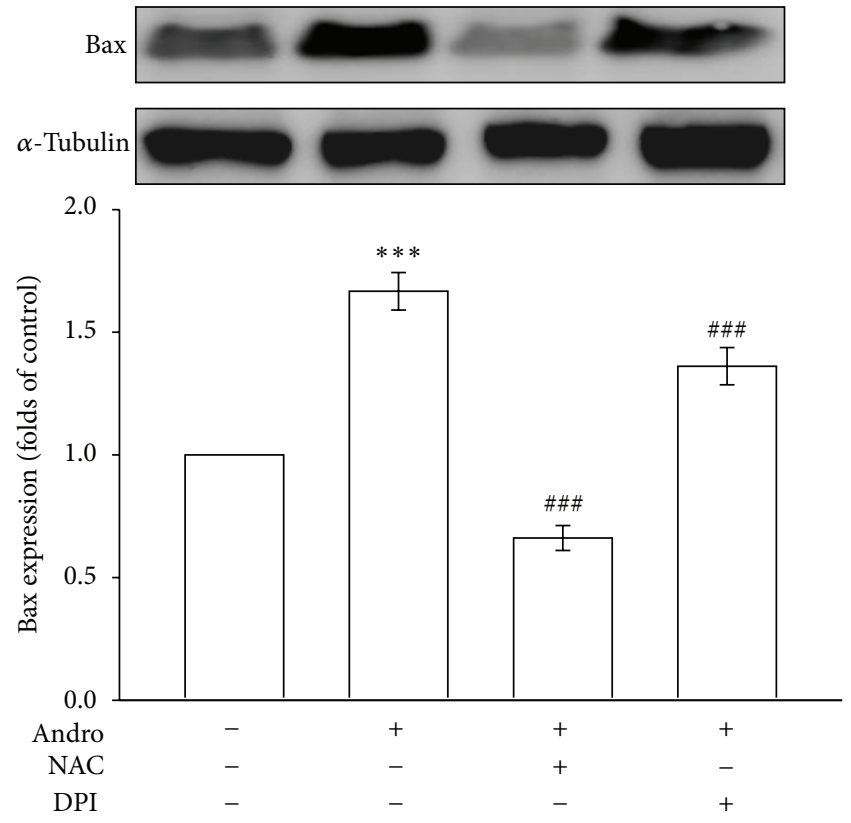

(b)

Active caspase-3

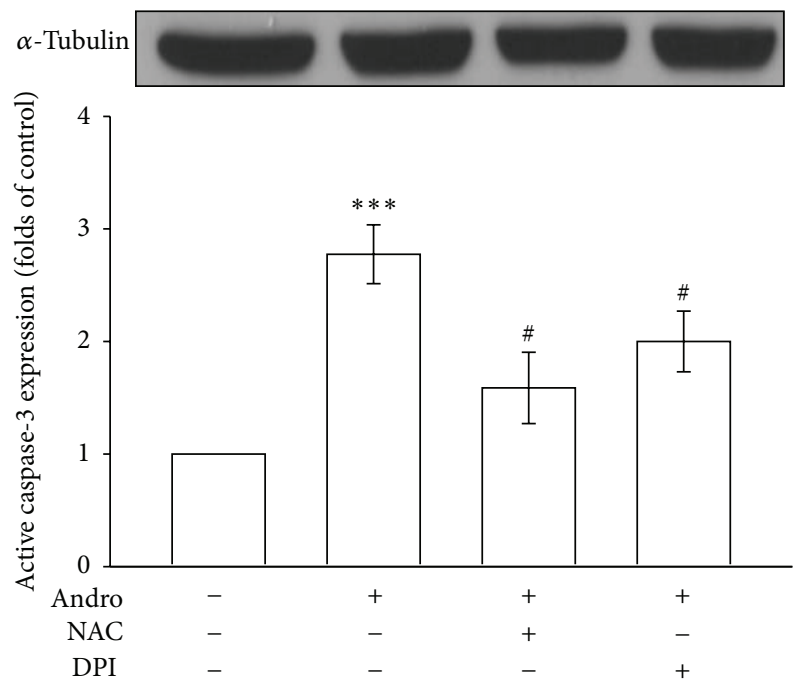

(c)

FIGURE 4: Effects of ROS scavengers on andrographolide-stimulated p53 activation, Bax, and active caspase-3 expression in rat VSMCs. (a) Cells were transiently transfected with PG-13-luc and Renilla-luc for $48 \mathrm{~h}$. After transfection, the cells were pretreated with a vehicle, $1 \mathrm{mM}$ NAC, or $10 \mu \mathrm{M}$ DPI for 30 min before being treated with $50 \mu \mathrm{M}$ andrographolide for another $24 \mathrm{~h}$. A PG13-luciferase assay was subsequently conducted. Cells were pretreated with a vehicle, $1 \mathrm{mM} \mathrm{NAC}$, or $10 \mu \mathrm{M}$ DPI for 30 min before being treated with $50 \mu \mathrm{M}$ andrographolide for $48 \mathrm{hr}$, and the expression of Bax (b) and active caspase-3 (c) was examined using immunoblotting. The data are presented as the mean \pm SEM (error bars: ${ }^{* *} P<0.01$ and ${ }^{* * *} P<0.001$, compared with the control group, and ${ }^{\#} P<0.05$, $^{\# \#} P<0.01$, and ${ }^{\# \#} P<0.001$, compared with the group treated only with andrographolide).

apoptosis involves the generation of ROS [25]. Therefore, we used a PGl3-Luc reporter construct that contained a p53 DNA-binding site linked to a basal promoter that controls the expression of a luciferase reporter gene [26] to examine whether p53 transactivation increases in cells exposed to andrographolide. As shown in Figure 4(a), cells treated with $50 \mu \mathrm{M}$ andrographolide for $24 \mathrm{~h}$ exhibited a $4.2 \pm 0.7$ fold increase in PG13-luciferase activity level compared with 
the control group $(P<0.01, n=5)$. Pretreating cells with NAC or DPI apparently inhibited the andrographolideinduced increase in PG13-luciferase activity $68.8 \%$ and $65.6 \%$, respectively $(n=5)$ (Figure $4(\mathrm{a})$ ).

It has been suggested that the activation of p53 regulated and promoted discrete steps of the apoptosis cascade such as the upregulation of Bax genes [27] and the overexpression of Bax accelerates apoptotic death through interaction with components of the permeability transition pore complex, causing the opening and rupture of its outer mitochondrial membrane [28]. As shown in Figure 4(b), treatment with $50 \mu \mathrm{M}$ andrographolide for $48 \mathrm{~h}$ significantly induced Bax expression $1.7 \pm 0.1$-fold compared with the control group $(P<0.001, n=3)$, whereas pretreatment with NAC or DPI significantly inhibited andrographolide-induced reductions in Bax expression 59\% and 18\%, respectively $(n=3)$. The expression levels of active caspase-3, an apoptoticpathway-related proapoptotic protein, were subsequently determined in andrographolide-treated VSMCs. As shown in Figure 4(c), treatment with andrographolide for $48 \mathrm{~h}$ significantly increased the levels of active caspase-3 $2.8 \pm 0.3$ fold at the concentration of $50 \mu \mathrm{M}$ compared with the control group $(P<0.001, n=4)$, whereas pretreatment with NAC or DPI significantly inhibited andrographolide-induced reductions in active caspase- 3 expression by $43 \%$ and $29 \%$, respectively $(n=4)$. These results suggest that Nox-mediated redox signaling induces p53 activation as well as Bax and active caspase-3 expression in andrographolide-treated rat VSMCs.

3.4. The Role of Ceramide Signaling in AndrographolideInduced p47phox Phosphorylation, Bax, and Active Caspase-3 Expression in Rat VSMCs. The precise mechanism involved in the andrographolide-induced phosphorylation of $\mathrm{p} 47 \mathrm{phox}$ in rat VSMCs remains unclear. A previous study reported ceramide to be a critical signaling molecule that mediates the activation of Nox in various cells [29]. In addition, we demonstrated that andrographolide can activate the nSMaseceramide cascade in rat VSMCs, and andrographolideinduced ceramide formation was markedly attenuated by 3OMS, an nSMase inhibitor [17]. As shown in Figure 5(a), pretreatment with 3 -OMS $(30 \mu \mathrm{M})$ for 30 min significantly inhibited andrographolide-induced $\mathrm{p} 47$ phox phosphorylation 38\% $(P<0.05, n=3)$. Pretreatment with 3-OMS also significantly diminished andrographolide-induced Bax and active caspase-3 expression in rat VSMCs (Figures 5(b) and $5(\mathrm{c})$ ).

\section{Discussion}

VSMCs represent a moving component of the vasculature and constitute the medial layer of blood vessels. VSMCs following pathological stimuli can adopt a "de-differentiated" phenotype or undergo hypertrophy and synthesize excess extracellular matrix and inflammatory cytokines, which divide and migrate toward the intima. The abnormal proliferation and reduced apoptosis can lead to excessive accumulation of VSMCs in the intima and media of atherosclerotic lesions involved [30]. A variation in the balance between the proliferation and apoptosis of VSMCs is considered to play a vital role in the development of atherosclerosis and cardiovascular diseases $[31,32]$. Thus, maintaining the alteration between the proliferation and apoptosis of VSMCs has been proposed as an effective therapeutic method for preventing and treating vascular diseases, including atherosclerosis [33]. Apoptosis (programmed cell death) in a wide range of physiological settings is to remove discarded cells [34]. Recent studies have indicated that andrographolide inhibits tumor growth by inducing cell cycle arrest $[13,14]$ or apoptosis $[15,16]$ in various types of cancer cells. In the present study, andrographolide was also observed to induce apoptosis in rat VSMCs, whereas no cytotoxic effect was observed (data not show), suggesting that andrographolide may be a potential therapeutic agent in VSMC-proliferation-related diseases.

The net balance between proliferation, apoptosis, and necrosis determines the extent of cell growth. A growing body of evidence now suggests that ROS play a role in both cellular necrosis and apoptosis [35]. Andrographolide was reported to induce ROS and caspase-dependent apoptosis in lymphoma cell lines and in primary tumor samples [36]. Therefore, we hypothesized that andrographolide might cause apoptosis in rat VSMCs through mechanisms that involve cellular redox systems. We determined that the effects of andrographolide were concentration related and accompanied by ROS generation (Figures 2 and 3(a)).

The proapoptotic protein Bax is known to cause apoptosis by disrupting mitochondrial integrity [37]. Yang et al. demonstrated that andrographolide induces the expression of Bax, activates caspases, and stimulates apoptosis in lymphoma cells [36]. Activation of p53 is known to increase the expression of Bax in response to selected stress signals [38]. A recent study observed that andrographolide can activate p53 through ROS-dependent to TRAIL-induced apoptosis in cancer cells [39]. Among $\mathrm{ROS}, \mathrm{O}_{2}{ }^{-}$is highly reactive and short lived and can spontaneously or enzymatically dismutate to a second signaling intermediate, $\mathrm{H}_{2} \mathrm{O}_{2}$, through superoxide dismutase. Although the production of $\mathrm{O}_{2}{ }^{-}$contributes to the primary biological activity of Nox, much of the signaling is mediated by the dismutation product $\mathrm{H}_{2} \mathrm{O}_{2}$. $\mathrm{H}_{2} \mathrm{O}_{2}$ is more stable than $\mathrm{O}_{2}{ }^{-}$and is capable of crossing biological membranes and inducing nucleus DNA damage to cause a p53-dependent pathway $[40,41]$. In the present study, andrographolide-induced p53 activation, Bax, and active caspase-3 expressions were significantly diminished by treatment with NAC and DPI. These data indicate the involvement of the ROS-mediated p53-Bax-caspase apoptotic pathway in andrographolide-induced VSMC apoptosis (Figure 4).

Noxs are multiprotein complexes of various compositions depending on the cell type. This enzyme, originally described in phagocytes, consists of 2 membrane-bound subunits (p22phox and Nox2) and 3 cytosolic subunits, such as p47phox, p67phox, and Racl (nonphagocytes) or Rac2 (phagocytes), which are recruited upon activation to the membrane-bound Nox/p22phox complex. VSMCs contain several sources of ROS, among which the Nox1 and Nox 2 are predominant. Barry-Lane et al. have suggested that $\mathrm{p} 47 \mathrm{phox}$ is the only subunit that is used specifically by Nox 2 and 


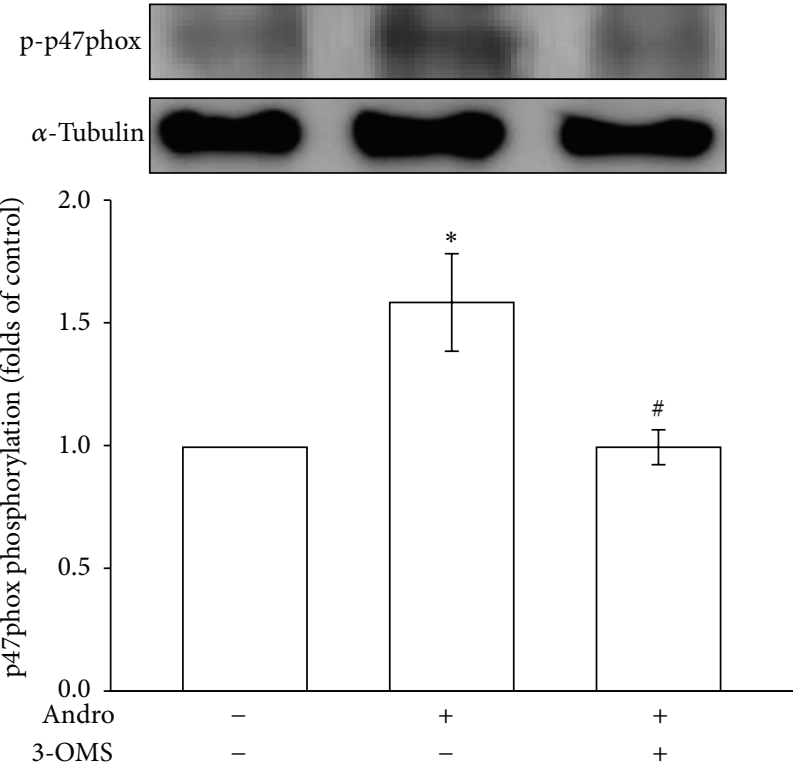

(a)

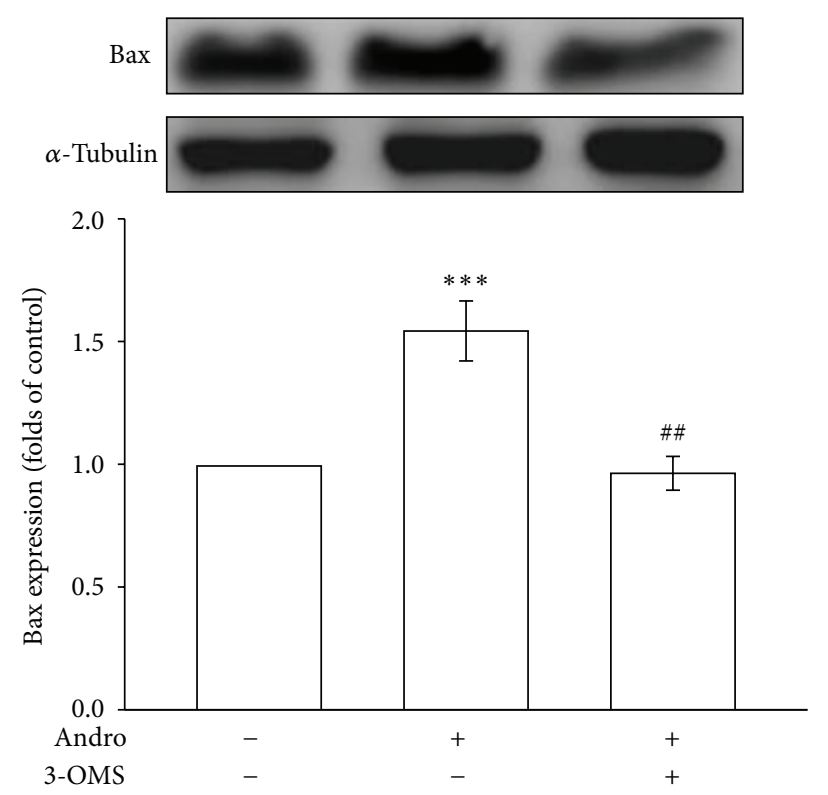

(b)
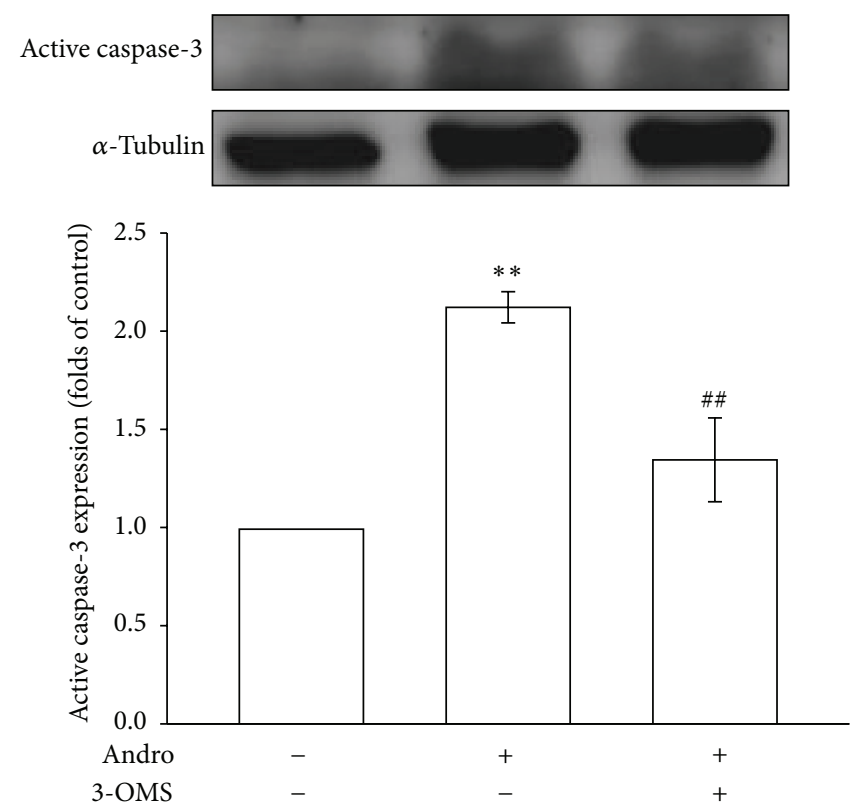

(c)

FIGURE 5: The role of ceramide signaling in andrographolide-induced p47phox phosphorylation, Bax, and active caspase-3 expression in rat VSMCs. Cells were pretreated with a vehicle or $30 \mu \mathrm{M} 3-\mathrm{OMS}$ for $30 \mathrm{~min}$ before being treated with $50 \mu \mathrm{M}$ andrographolide for 10 min (a), or $48 \mathrm{~h} \mathrm{(b}$ and c). The extent of p47phox phosphorylation (a), Bax (b), or active caspase-3 expression (c) was examined. The data are presented as the mean \pm SEM (error bars: ${ }^{*} P<0.05,{ }^{* *} P<0.01$, and ${ }^{* * *} P<0.001$, compared with the control group, and ${ }^{\# \#} P<0.01$ and ${ }^{\# \# \#} P<0.001$, compared with the group treated only with andrographolide).

by Noxl expressed in VSMCs [42]. Furthermore, p47phox for oxidase activation requires a phosphorylated serine at position 359 that is absolutely required for oxidase activity and must be phosphorylated to allow translocation [43]. A functional role for p47phox has also been shown using VSMCs from p47phox knockout mice, in which the agonist stimulation of ROS was reduced $[44,45]$. In the present study, we observed that DPI, a Nox inhibitor, significantly restored ROS formation and apoptosis-inducing activity in andrographolide-treated rat VSMCs, and the incubation of andrographolide apparently increased the phosphorylation of p47phox, a Nox subunit. These data collectively indicate that Nox-mediated redox signaling plays a crucial role in rat VSMCs treated with andrographolide. However, the precise mechanism involved in the andrographolide-induced phosphorylation of $\mathrm{p} 47 \mathrm{phox}$ in rat VSMCs remains unclear. 


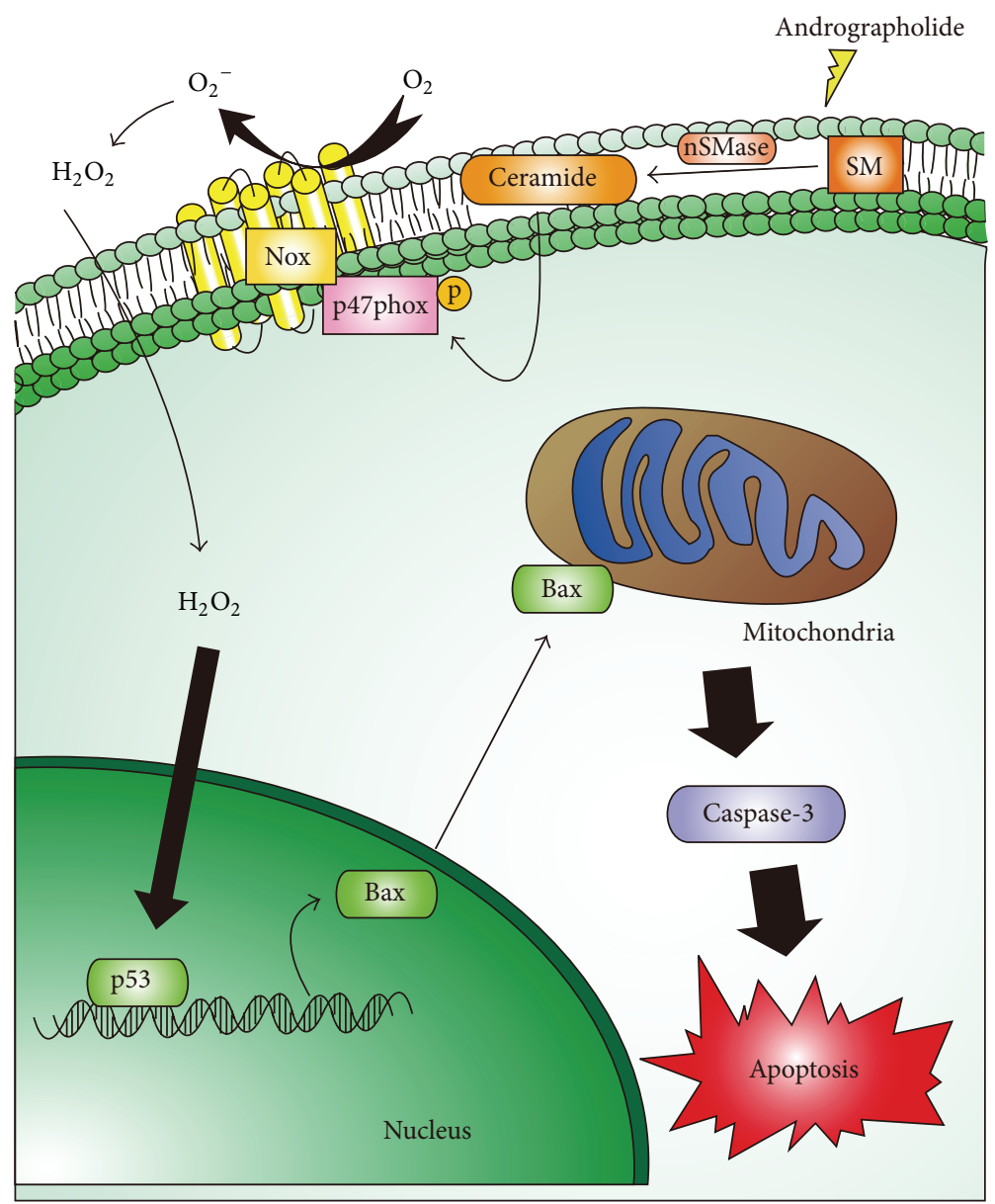

FIGURE 6: Hypothetical scheme of the signal pathways in andrographolide-induced rat VSMC apoptosis. Andrographolide stimulated the ceramide-mediated signal events, resulting in the activation of the p47phox-ROS cascade, ultimately stimulating active caspase-3 expression and VSMC apoptosis. Nox produces superoxide $\left(\mathrm{O}_{2}{ }^{-}\right)$, followed by the induction of $\mathrm{H}_{2} \mathrm{O}_{2} \cdot \mathrm{H}_{2} \mathrm{O}_{2}$ is capable of inducing DNA damage to cause p53 activation, which can lead Bax and active caspase-3 expression. nSMase: neutral sphingomyelinase; SM: sphingomyelinase; Nox: NADPH oxidase.

Ceramide, the central core lipid in the metabolism of sphingolipids, is produced through hydrolysis of complex sphingolipids, such as sphingomyelin, by mammalian SMases or through the acylation of a long-chain sphingoid base (sphingosine) in a de novo biosynthetic pathway. The SMases and its role in ceramide metabolism are the most extensively studied. Recent studies have demonstrated that ceramide increased in endothelial cells exposed to death factors, including tumor necrosis factor $\alpha$, interleukin 2, and endostatin, and in ischemic reperfused myocardium [46, 47]. In these studies, the ceramide signaling pathway has been confirmed to be involved in the activation of Nox and consequent $\mathrm{O}_{2}{ }^{-}$production $[48,49]$. Ceramide also enhances ROS formation in mammalian cells by straightly raising the permeability of mitochondrial membranes to cytochrome $\mathrm{c}$ [50] and restraining the isolated mitochondria complex III [51]. In addition, the accumulation of ceramides caused by the activation of SMases has been observed in response to various stimuli, such as oxidants and heat stress $[52,53]$. On the other hand, our previous study found that andrographolide can directly enhance ceramide level in VSMCs, and this phenomenon was markedly attenuated by 3-OMS [17]. In the present study, we observed that 3-OMS apparently abolished andrographolide-induced p47phox phosphorylation, Bax, and active caspase-3 expression in rat VSMCs (Figure 5). Taken together, these results indicate that andrographolide increases the turnover of sphingomyelin in rat VSMCs, and this lipid-signaling pathway may mediate the action of the andrographolide-induced activation of Nox, resulting in $\mathrm{O}_{2}{ }^{-}$ production and apoptosis-inducing activity in rat VSMCs.

In the present study, we showed that andrographolide, the active component of the plant $A$. paniculata, has the ability to reduce cell viability in rat VSMCs. The in-depth mechanism of its apoptosis-inducing activity is related to the Nox-mediated redox signaling of cells, because this signaling is blocked by NAC and DPI. In addition, this is the first study to indicate the role of the ceramide-p47phox signaling pathway in andrographolide-induced ROS-mediated cell apoptosis (Figure 6). In conclusion, we showed that the ceramide-p47phox-ROS signaling cascade may contribute to andrographolide-induced VSMC apoptosis. Using this novel natural lactone diterpenoid as a therapeutic strategy 
for cardiovascular disorders involving VSMC proliferation and atherogenesis warrants further preclinical and clinical investigation.

\section{Conflict of Interests}

The authors declare no conflict of interests.

\section{Acknowledgments}

This work was supported by Grants from the National Science Council, Taiwan (NSC97-2320-B-038-016-MY3 and NSC1002320-B-038-021-MY3), and Taipei Medical University (TMUR-100-03 and TMU102-AE1-B20).

\section{References}

[1] K. K. Koh, S. H. Han, P. C. Oh, E. K. Shin, and M. J. Quon, "Combination therapy for treatment or prevention of atherosclerosis: focus on the lipid-RAAS interaction," Atherosclerosis, vol. 209, no. 2, pp. 307-313, 2010.

[2] V. J. Dzau, R. C. Braun-Dullaeus, and D. G. Sedding, "Vascular proliferation and atherosclerosis: new perspectives and therapeutic strategies," Nature Medicine, vol. 8, no. 11, pp. 1249-1256, 2002.

[3] Z. H. Mnjoyan and K. Fujise, "Profound negative regulatory effects by resveratrol on vascular smooth muscle cells: a role of p53-p21WAF1/CIP1 pathway," Biochemical and Biophysical Research Communications, vol. 311, no. 2, pp. 546-552, 2003.

[4] K. Walsh, R. C. Smith, and H.-S. Kim, "Vascular cell apoptosis in remodeling, restenosis, and plaque rupture," Circulation Research, vol. 87, no. 3, pp. 184-188, 2000.

[5] D. K. M. Han, C. C. Haudenschild, M. K. Hong, B. T. Tinkle, M. B. Leon, and G. Liau, "Evidence for apoptosis in human atherogenesis and in a rat vascular injury model," American Journal of Pathology, vol. 147, no. 2, pp. 267-277, 1995.

[6] E. Wang, R. Marcotte, and E. Petroulakis, "Signaling pathway for apoptosis: a racetrack for life or death," Journal of Cellular Biochemistry, vol. 76, supplement 32-33, pp. 95-102, 1999.

[7] L. Leduc, E. Levy, M. Bouity-Voubou, and E. Delvin, "Fetal programming of atherosclerosis: possible role of the mitochondria," European Journal of Obstetrics Gynecology and Reproductive Biology, vol. 149, no. 2, pp. 127-130, 2010.

[8] K. K. Griendling, C. A. Minieri, J. D. Ollerenshaw, and R. W. Alexander, "Angiotensin II stimulates NADH and NADPH oxidase activity in cultured vascular smooth muscle cells," Circulation Research, vol. 74, no. 6, pp. 1141-1148, 1994.

[9] B. M. Babior, "NADPH oxidase," Current Opinion in Immunology, vol. 16, no. 1, pp. 42-47, 2004.

[10] K. K. Griendling, D. Sorescu, and M. Ushio-Fukai, "NAD(P)H oxidase: role in cardiovascular biology and disease," Circulation Research, vol. 86, no. 5, pp. 494-501, 2000.

[11] J. T. Coon and E. Ernst, "Andrographis paniculata in the treatment of upper respiratory tract infections: a systematic review of safety and efficacy," Planta Medica, vol. 70, no. 4, pp. 293-298, 2004.

[12] N. Poolsup, C. Suthisisang, S. Prathanturarug, A. Asawamekin, and U. Chanchareon, "Andrographis paniculata in the symptomatic treatment of uncomplicated upper respiratory tract infection: systematic review of randomized controlled trials,"
Journal of Clinical Pharmacy and Therapeutics, vol. 29, no. 1, pp. 37-45, 2004.

[13] H.-Y. Cheung, S.-H. Cheung, J. Li et al., "Andrographolide isolated from Andrographis paniculata induces cell cycle arrest and mitochondrial-mediated apoptosis in human leukemic HL60 cells," Planta Medica, vol. 71, no. 12, pp. 1106-1111, 2005.

[14] J. Li, H.-Y. Cheung, Z. Zhang, G. K. L. Chan, and W.-F. Fong, "Andrographolide induces cell cycle arrest at G2/M phase and cell death in HepG2 cells via alteration of reactive oxygen species," European Journal of Pharmacology, vol. 568, no. 1-3, pp. 31-44, 2007.

[15] J. Zhou, S. Zhang, O. Choon-Nam, and H.-M. Shen, "Critical role of pro-apoptotic Bcl-2 family members in andrographolide-induced apoptosis in human cancer cells," Biochemical Pharmacology, vol. 72, no. 2, pp. 132-144, 2006.

[16] M. T. Cheung, R. Ramalingam, K. K. Lau, W. L. Chiang, and S. K. Chiu, "Cell type-dependent effects of andrographolide on human cancer cell lines," Life Sciences, vol. 91, no. 15-16, pp. 751760, 2012.

[17] C. Y. Hsieh, M. J. Hsu, G. Hsiao et al., "Andrographolide enhances nuclear factor- $\kappa \mathrm{B}$ subunit p65 Ser536 dephosphorylation through activation of protein phosphatase $2 \mathrm{~A}$ in vascular smooth muscle cells," Journal of Biological Chemistry, vol. 286, no. 8, pp. 5942-5955, 2011.

[18] W.-J. Lu, J.-J. Lee, D.-S. Chou et al., "A novel role of andrographolide, an NF-kappa B inhibitor, on inhibition of platelet activation: the pivotal mechanisms of endothelial nitric oxide synthase/cyclic GMP," Journal of Molecular Medicine, vol. 89, no. 12, pp. 1261-1273, 2011.

[19] W. J. Lu, K. H. Lin, M. J. Hsu et al., "Suppression of NFkappaB signaling by andrographolide with a novel mechanism in human platelets: regulatory roles of the p38 MAPK-hydroxyl radical-ERK2 cascade," Biochemical Pharmacology, vol. 84, no. 7, pp. 914-924, 2012.

[20] G. Hsiao, M.-Y. Shen, W.-C. Chang et al., "A novel antioxidant, octyl caffeate, suppression of LPS/IFN- $\gamma$-induced inducible nitric oxide synthase gene expression in rat aortic smooth muscle cells," Biochemical Pharmacology, vol. 65, no. 8, pp. 13831392, 2003.

[21] T. Mosmann, "Rapid colorimetric assay for cellular growth and survival: application to proliferation and cytotoxicity assays," Journal of Immunological Methods, vol. 65, no. 1-2, pp. 55-63, 1983.

[22] Y. Shi, R. Niculescu, D. Wang, S. Patel, K. L. Davenpeck, and A. Zalewski, "Increased NAD $(\mathrm{P}) \mathrm{H}$ oxidase and reactive oxygen species in coronary arteries after balloon injury," Arteriosclerosis, Thrombosis, and Vascular Biology, vol. 21, no. 5, pp. 739-745, 2001.

[23] L. Wang, L.-H. Zhu, H. Jiang et al., "Grape seed proanthocyanidins attenuate vascular smooth muscle cell proliferation via blocking phosphatidylinositol 3-kinase-dependent signaling pathways," Journal of Cellular Physiology, vol. 223, no. 3, pp. 713-726, 2010.

[24] D. Uberti, E. Yavin, S. Gil, K.-R. Ayasola, N. Goldfinger, and V. Rotter, "Hydrogen peroxide induces nuclear translocation of p53 and apoptosis in cells of oligodendroglia origin," Molecular Brain Research, vol. 65, no. 2, pp. 167-175, 1999.

[25] P.-F. Li, R. Dietz, and R. von Harsdorf, "p53 regulates mitochondrial membrane potential through reactive oxygen species and induces cytochrome c-independent apoptosis blocked by Bcl2," The EMBO Journal, vol. 18, no. 21, pp. 6027-6036, 1999. 
[26] W. S. El-Deiry, T. Tokino, V. E. Velculescu et al., "WAF1, a potential mediator of p53 tumor suppression," Cell, vol. 75, no. 4, pp. 817-825, 1993.

[27] T. Miyashita and J. C. Reed, "Tumor suppressor p53 is a direct transcriptional activator of the human bax gene," Cell, vol. 80, no. 2, pp. 293-299, 1995.

[28] I. Marzo, C. Brenner, N. Zamzami et al., "Bax and adenine nucleotide translocator cooperate in the mitochondrial control of apoptosis," Science, vol. 281, no. 5385, pp. 2027-2031, 1998.

[29] M. Frech, M. Andjelkovic, E. Ingley, K. K. Reddy, J. R. Falck, and B. A. Hemmings, "High affinity binding of inositol phosphates and phosphoinositides to the pleckstrin homology domain of RAC/protein kinase B and their influence on kinase activity," Journal of Biological Chemistry, vol. 272, no. 13, pp. 8474-8481, 1997.

[30] G. Evan and T. Littlewood, "A matter of life and cell death," Science, vol. 281, no. 5381, pp. 1317-1322, 1998.

[31] J.-K. Hsieh, D. Kletsas, G. Clunn, A. D. Hughes, M. Schachter, and C. Demoliou-Mason, "p53, p21(WAF1/CIP1) and MDM2 involvement in the proliferation and apoptosis in an in vitro model of conditionally immortalized human vascular smooth muscle cells," Arteriosclerosis, Thrombosis, and Vascular Biology, vol. 20, no. 4, pp. 973-981, 2000.

[32] M. Clarke and M. Bennett, "The emerging role of vascular smooth muscle cell apoptosis in atherosclerosis and plaque stability," American Journal of Nephrology, vol. 26, no. 6, pp. 531535, 2007.

[33] S. Meiners, M. Laule, W. Rother et al., "Ubiquitin-proteasome pathway as a new target for the prevention of restenosis," Circulation, vol. 105, no. 4, pp. 483-489, 2002.

[34] K. L. King and J. A. Cidlowski, "Cell cycle regulation and apoptosis," Annual Review of Physiology, vol. 60, pp. 601-617, 1998.

[35] V. Goossens, J. Grooten, K. de Vos, and W. Fiers, "Direct evidence for tumor necrosis factor-induced mitochondrial reactive oxygen intermediates and their involvement in cytotoxicity," Proceedings of the National Academy of Sciences of the United States of America, vol. 92, no. 18, pp. 8115-8119, 1995.

[36] S. Yang, A. M. Evens, S. Prachand et al., "Mitochondrialmediated apoptosis in lymphoma cells by the diterpenoid lactone andrographolide, the active component of Andrographis paniculata," Clinical Cancer Research, vol. 16, no. 19, pp. 4755$4768,2010$.

[37] M. C. Wei, W.-X. Zong, E. H.-Y. Cheng et al., "Proapoptotic BAX and BAK: a requisite gateway to mitochondrial dysfunction and death," Science, vol. 292, no. 5517, pp. 727-730, 2001.

[38] H. M. Zhang, J. Yuan, P. Cheung et al., "Gamma interferoninducible protein 10 induces HeLa cell apoptosis through a p53-dependent pathway initiated by suppression of human papillomavirus type 18 E6 and E7 expression," Molecular and Cellular Biology, vol. 25, no. 14, pp. 6247-6258, 2005.

[39] J. Zhou, G.-D. Lu, C.-S. Ong, C.-N. Ong, and H.-M. Shen, "Andrographolide sensitizes cancer cells to TRAIL-induced apoptosis via p53-mediated death receptor 4 up-regulation," Molecular Cancer Therapeutics, vol. 7, no. 7, pp. 2170-2180, 2008.

[40] W. G. Nelson and M. B. Kastan, "DNA strand breaks: the DNA template alterations that trigger p53-dependent DNA damage response pathways," Molecular and Cellular Biology, vol. 14, no. 3, pp. 1815-1823, 1994.

[41] F. M. Yakes and B. van Houten, "Mitochondrial DNA damage is more extensive and persists longer than nuclear DNA damage in human cells following oxidative stress," Proceedings of the National Academy of Sciences of the United States of America, vol. 94, no. 2, pp. 514-519, 1997.

[42] P. A. Barry-Lane, C. Patterson, M. van der Merwe et al., "p47phox is required for atherosclerotic lesion progression in ApoE-/- mice," Journal of Clinical Investigation, vol. 108, no. 10, pp. 1513-1522, 2001.

[43] J. L. Johnson, J.-W. Park, J. El Benna, L. P. Faust, O. Inanami, and B. M. Babior, "Activation of p47(PHOX), a cytosolic subunit of the leukocyte NADPH oxidase: phosphorylation of Ser-359 or Ser-370 precedes phosphorylation at other sites and is required for activity," Journal of Biological Chemistry, vol. 273, no. 52, pp. 35147-35152, 1998.

[44] M. C. Lavigne, H. L. Malech, S. M. Holland, and T. L. Leto, "Genetic demonstration of p47phox-dependent superoxide anion production in murine vascular smooth muscle cells," Circulation, vol. 104, no. 1, pp. 79-84, 2001.

[45] R. P. Brandes, F. J. Miller, S. Beer et al., “The vascular NADPH oxidase subunit p47phox is involved in redox-mediated gene expression," Free Radical Biology and Medicine, vol. 32, no. 11, pp. 1116-1122, 2002.

[46] D. X. Zhang, R. M. Fryer, A. K. Hsu et al., "Production and metabolism of ceramide in normal and ischemic-reperfused myocardium of rats," Basic Research in Cardiology, vol. 96, no. 3, pp. 267-274, 2001.

[47] D. X. Zhang, A.-P. Zou, and P.-L. Li, "Ceramide-induced activation of NADPH oxidase and endothelial dysfunction in small coronary arteries," American Journal of Physiology-Heart and Circulatory Physiology, vol. 284, no. 2, pp. H605-H612, 2003.

[48] G. Sahni, S. A. Khan, and A. S. Acharya, "Chemistry of the 'molecular trap' of protease-catalyzed splicing reaction of complementary segments of $\alpha$-subunit of hemoglobin A," Journal of Protein Chemistry, vol. 17, no. 7, pp. 669-678, 1998.

[49] N. Embade, P. F. Valeron, S. Aznar, E. Lopez-Collazo, and J. C. Lacal, "Apoptosis induced by Rac GTPase correlates with induction of FasL and ceramides production," Molecular Biology of the Cell, vol. 11, no. 12, pp. 4347-4358, 2000.

[50] L. J. Siskind, S. Fluss, M. Bui, and M. Colombini, "Sphingosine forms channels in membranes that differ greatly from those formed by ceramide," Journal of Bioenergetics and Biomembranes, vol. 37, no. 4, pp. 227-236, 2005.

[51] T. I. Gudz, K.-Y. Tserng, and C. L. Hoppel, "Direct inhibition of mitochondrial respiratory chain complex III by cell-permeable ceramide," Journal of Biological Chemistry, vol. 272, no. 39, pp. 24154-24158, 1997.

[52] N. Bartke and Y. A. Hannun, "Bioactive sphingolipids: metabolism and function," Journal of lipid research, vol. 50, pp. S91-96, 2009.

[53] Y. A. Hannun and L. M. Obeid, "Principles of bioactive lipid signalling: lessons from sphingolipids," Nature Reviews Molecular Cell Biology, vol. 9, no. 2, pp. 139-150, 2008. 


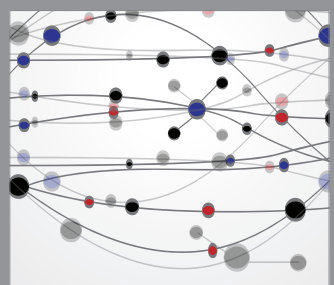

The Scientific World Journal
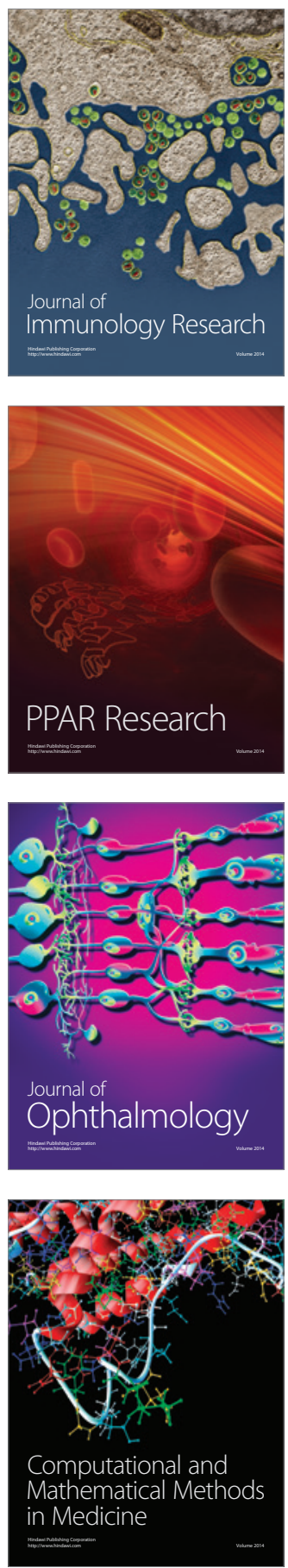

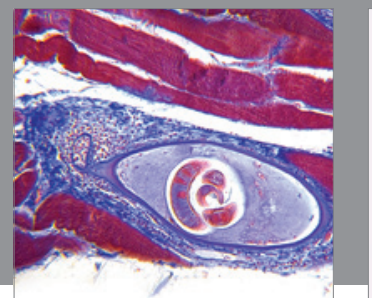

Gastroenterology

Research and Practice
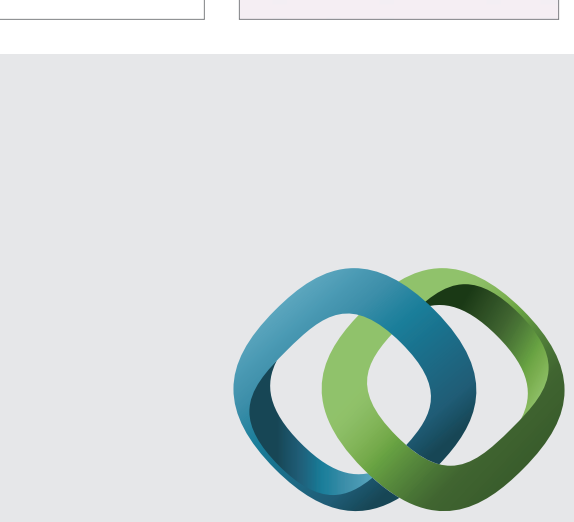

\section{Hindawi}

Submit your manuscripts at

http://www.hindawi.com
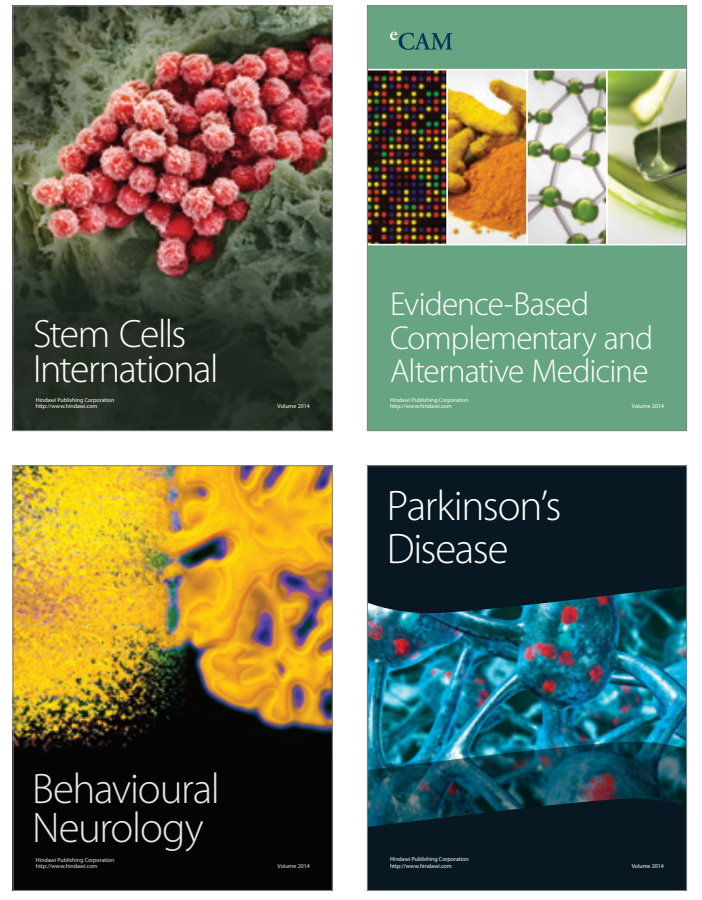
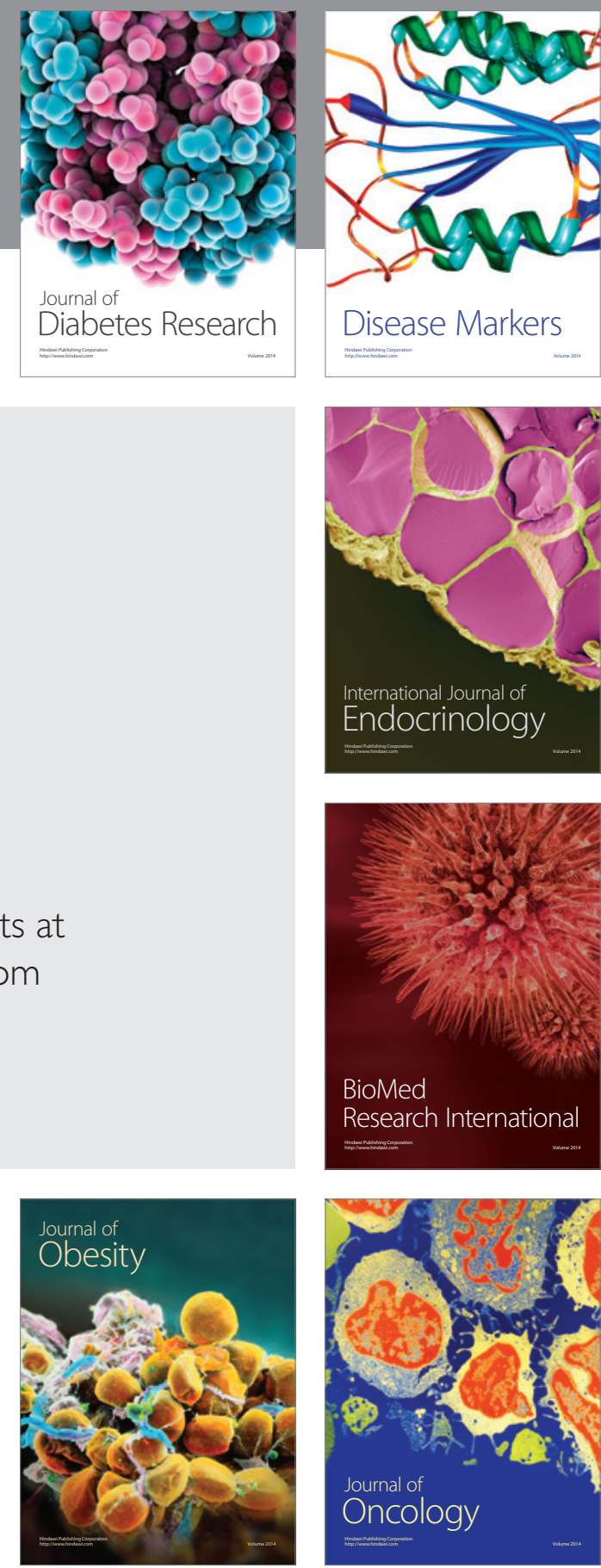

Disease Markers
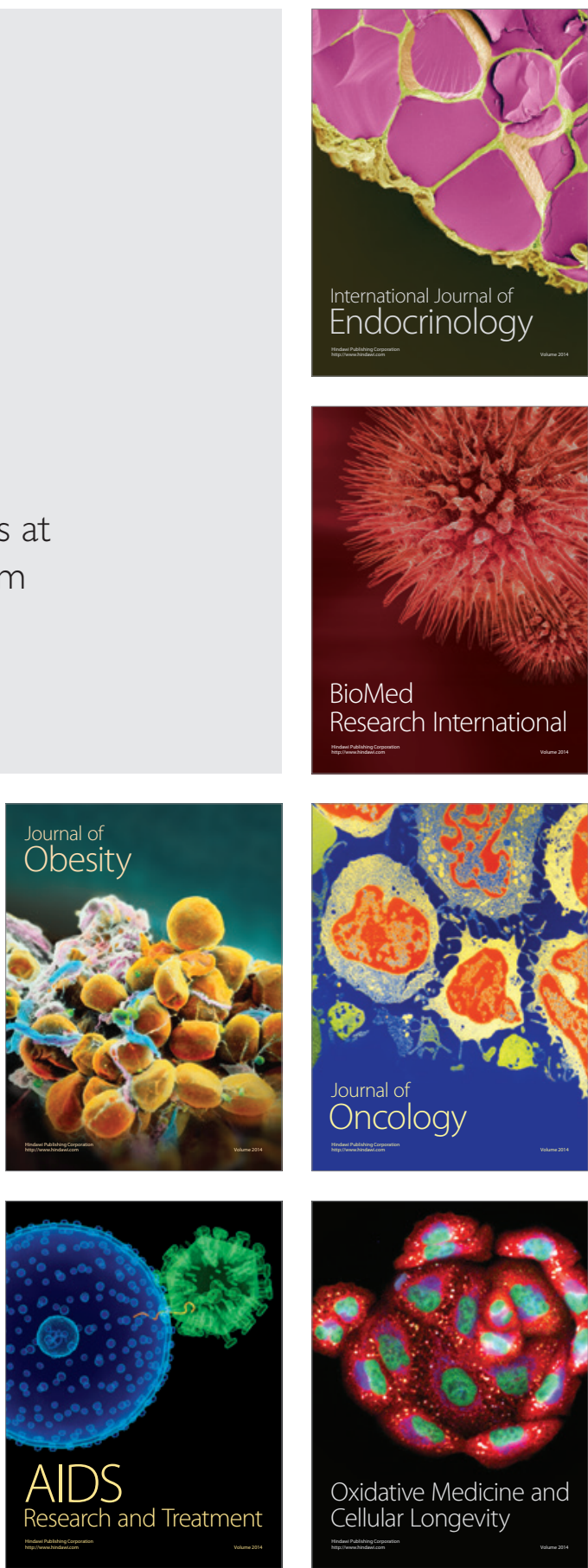